\title{
MicroRNA-214 enriched exosomes from human cerebral endothelial cells (hCEC) sensitize hepatocellular carcinoma to anti-cancer drugs
}

\author{
Louie Semaan ${ }^{1, *}$, Qingning Zeng ${ }^{1, *}$, Yong Lu ${ }^{1, *}$, Yi Zhang ${ }^{1}$, Mehdi Mohamad Zreik ${ }^{1,4}$, \\ Mohamad Baqer Chamseddine ${ }^{1,5}$, Michael Chopp ${ }^{1,3}$, Zheng Gang Zhang ${ }^{1, \#}$ and Dilip \\ Moonka ${ }^{2, \#}$ \\ ${ }^{1}$ Department of Neurology, Henry Ford Hospital, Detroit, MI 48202, USA \\ ${ }^{2}$ Division of Gastroenterology and Hepatology, Henry Ford Hospital, Detroit, MI 48202, USA \\ ${ }^{3}$ Department of Physics, Oakland University, Rochester, MI 48309, USA \\ ${ }^{4}$ Department of Neurology, School of Medicine, Wayne State University, Detroit, MI 48202, USA \\ ${ }^{5}$ Department of Natural Sciences, University of Michigan-Dearborn, Dearborn, MI 48128, USA \\ *These authors contributed equally to this work \\ ${ }^{\text {\#} C o n t r i b u t e d ~ e q u a l l y ~ a s ~ s e n i o r ~ a u t h o r s ~}$ \\ Correspondence to: Zheng Gang Zhang, email: Zzhangl@hfhs.org \\ Dilip Moonka, email: DMoonkal @hfhs.org \\ Keywords: hepatocellular carcinoma (HCC); human cerebral endothelial cells-derived exosomes; microRNA-214; therapeutic \\ efficacy; anti-cancer drug \\ Received: November 17, $2020 \quad$ Accepted: January 19, $2021 \quad$ Published: February 02, 2021
}

Copyright: ( 2021 Semaan et al. This is an open access article distributed under the terms of the Creative Commons Attribution License (CC BY 3.0), which permits unrestricted use, distribution, and reproduction in any medium, provided the original author and source are credited.

\section{ABSTRACT}

Hepatocellular carcinoma (HCC) is the most common primary liver tumor worldwide. Current medical therapy for HCC has limited efficacy. The present study tests the hypothesis that human cerebral endothelial cell-derived exosomes carrying elevated miR-214 (hCEC-Exo-214) can amplify the efficacy of anti-cancer drugs on HCC cells. Treatment of HepG2 and Hep3B cells with hCEC-Exo-214 in combination with anti-cancer agents, oxaliplatin or sorafenib, significantly reduced cancer cell viability and invasion compared with monotherapy with either drug. Additionally, the therapeutic effect of the combination therapy was detected in primary tumor cells derived from patients with HCC. The ability of hCEC-Exo-214 in sensitizing HCC cells to anti-cancer drugs was specific, in that combination therapy did not affect the viability and invasion of human liver epithelial cells and non-cancer primary cells. Furthermore, compared to monotherapy with oxaliplatin and sorafenib, hCECExo-214 in combination with either drug substantially reduced protein levels of P-glycoprotein (P-gP) and splicing factor 3B subunit 3 (SF3B3) in HCC cells. P-gp and SF3B3 are among miR-214 target genes and are known to mediate drug resistance and cancer cell proliferation, respectively. In conclusion, the present in vitro study provides evidence that hCEC-Exo-214 significantly enhances the anti-tumor efficacy of oxaliplatin and sorafenib on HCC cells.

\section{INTRODUCTION}

Liver cancer is the fifth leading cause of cancer death worldwide. Hepatocellular carcinoma (HCC) is the dominant form of primary liver cancer, accounting for $85-90 \%$ of cases [1]. Surgical resection and liver transplantation are curative options but are offered to a small percentage of eligible patients [2]. Patients with advanced liver cancer, have limited medical options including sorafenib, which increases overall survival by less than three months [3]. Drug resistance is often evident within several months of initial treatment [4]. The low 
efficacy and high adverse side effect profile of currently available therapy provide a compelling need for more effective treatments [5].

MicroRNAs (miRNAs) are non-coding, small regulatory RNAs that target the 3 '-untranslated region (3'UTR) of mRNAs and negatively regulate gene expression at the post-transcriptional level $[6,7]$. miRNAs are key players in cancer biology, affecting molecular pathways involved in cell proliferation, angiogenesis, invasion, metastasis, and apoptosis in cancer progression $[8,9]$. miRNAs help mediate HCC pathogenesis $[10,11]$. miR-214, specifically, appears to function as a tumor suppressor in HCC by inhibiting cell proliferation, invasion, angiogenesis, and metastasis $[12,13]$. Downregulation of miR-214 has been detected in patients with HCC and in HCC cell lines [14-16]. miR-214 targets genes including hepatoma-derived growth factor (HDGF) [17], fibroblast growth factor receptor 1 (FGFR1) [18], $\beta$-catenin [14], and Wnt3a [19]. Upregulation of miR-214, therefore, may have a potential therapeutic role in HCC. However, to date, systemic delivery of RNAs, including miRNAs, have had limited therapeutic efficacy in cancer therapy [20].

Exosomes are cell-derived extracellular nanovesicles $(\sim 30-150 \mathrm{~nm})$ found in a wide range of biofluids and tissues [21]. They transport biologically active molecules including proteins, lipids, DNA, and RNA as cargo and facilitate local and long-distance intercellular communication [22-25]. Although essentially all eukaryotic cell types produce exosomes, emerging evidence has shown that exosome cargos differ greatly depending on their cell of origin [26]. Tumor cellderived exosomes are actively involved in metastatic niche formation, cancer progression, immune function regulation, and drug resistance [27-31]. Blood-derived exosomes are potential diagnostic and prognostic biomarkers for HCC [32-34]. In addition, use of exosomes as a vehicle to carry chemo-drugs, proteins, and miRNAs to treat cancer is being actively investigated [35-38]. The majority of intravenously administered exogenous exosomes are taken up by liver [39], making the use of exosomes to treat liver cancer especially appealing. Indeed, several studies have investigated the effect of engineered exosomes on liver cancer [40-42]. For example, mesenchymal stem cell (MSC)-derived exosomes carrying elevated miR-122 [43] and miR-199 [44] increase anti-cancer drug sensitivity of HCC cells to sorafenib and doxorubicin, respectively.

We previously demonstrated that engineered human cerebral endothelial cell-derived exosomes carrying elevated miR-214 (hCEC-Exo-214) sensitize ovarian cancer cells to chemotherapeutic agents [45]. In the present study, we test the hypothesis that miR-214 enriched exosomes can enhance the effect of anti-cancer drugs, oxaliplatin and sorafenib, on HCC cells.

\section{RESULTS}

\section{Downregulation of miR-214 in hepatocellular carcinoma cells}

miRNAs including miR-214 are involved in the development of HCC. We examined miR-214 expression in two HCC cell lines, HepG2 and Hep3B. Quantitative RT-PCR analysis showed that, compared to normal human liver epithelial cells (THLE-2), HepG2 and Hep3B cells exhibited an approximate 50 and 70\% significant reduction in miR-214 expression, respectively, whereas miR-92 expression was upregulated in HCC cells (Figure 1A). Additionally, we measured miR-214 levels in liver tumor tissues acquired from patients with HCC who had undergone tumor resection. We found that, compared to non-tumor liver tissue from the same individuals, 3 of $5(60 \%)$ tumor tissues showed reduced miR-214 levels (Figure 1B). These data are consistent with reports by others $[14-16,19,46]$ and suggest that miR214 is involved in HCC.

\section{Engineered hCEC-exosomes carrying elevated miR-214 (hCEC-Exo-214) enhance HCC sensitivity to anti-cancer drugs}

Overexpression of miR-214 in SK-Hep1 cells inhibits tumor cell growth [14, 17]. Using hCEC-Exo-214, we have demonstrated that the engineered hCEC-Exo-214 sensitize ovarian cancer cells to chemotherapeutic agents [45]. hCEC-Exo-214 were isolated from the supernatant of hCECs transfected with a lentivector expressing premiR-214 by means of differential ultracentrifugation. Isolated extracellular vesicles had a mean size of $104 \mathrm{~nm}$ and exhibited donut-shaped morphology demonstrated by Nanoparticle Tracking Analysis (NTA) and transmission electron microscopy (TEM), respectively (Figure $1 \mathrm{C}$ and 1D). Western blot analysis revealed that these extracellular vesicles expressed exosomal marker proteins, CD9, CD63, and Alix (Figure 1E). Quantitative RT-PCR showed that, compared to non-transfected hCECs, hCECs transfected with pre-miR-214 had upregulated miR-214. hCECExo-214 had an approximately 11-fold increase in miR214 compared to naïve hCEC-Exo (Figure 1F).

hCEC-Exo-214, alone and in combination with anticancer drugs, were evaluated for their effect on $\mathrm{HepG} 2$ and Hep3B cells. Neither naïve hCEC-Exo nor hCECExo-214 alone at doses of $10^{7}, 10^{8}$, and $10^{9}$ particles $/ \mathrm{ml}$ affected HCC cell viability measured by the MTT assay (Figure 2A). Oxaliplatin and sorafenib by themselves decreased cell viability of both HepG2 and Hep3B cells in a dose-dependent manner (Figure 2A and Supplementary Figure 1), consistent with previous reports [47-49]. Based on the dose response data, a dose at $0.0625 \mu \mathrm{M}$ of oxaliplatin was selected for HepG2 and Hep3B cells, 
while a dose of $1.2 \mu \mathrm{M}$ or $0.8 \mu \mathrm{M}$ of sorafenib was selected for HepG2 or Hep3B cells, respectively (Supplementary Figure 1). Naïve hCEC-Exo and hCEC-Exo-214 were evaluated to determine whether they enhanced the effect of oxaliplatin or sorafenib on HCC viability. The MTT analysis showed that naïve hCEC-Exo or hCEC-Exo-214 in combination with oxaliplatin or sorafenib significantly reduced viable HepG2 and Hep3B cells in an exosomal concentration dependent manner with the most robust reduction at the highest concentration $\left(10^{9}\right.$ particles $\left./ \mathrm{ml}\right)$

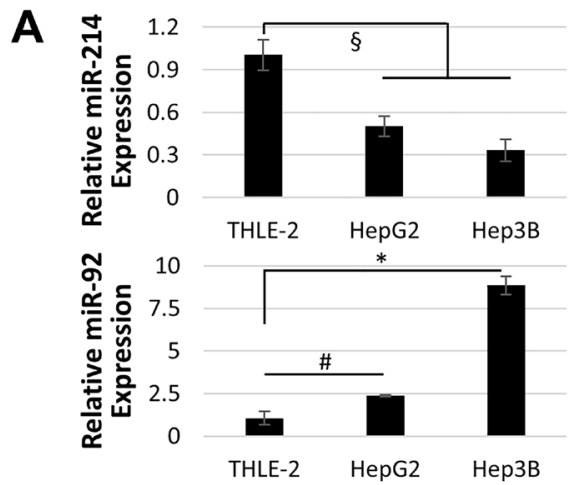

\section{C}

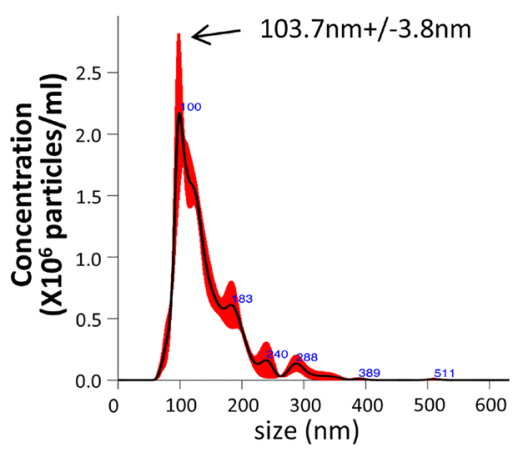

E

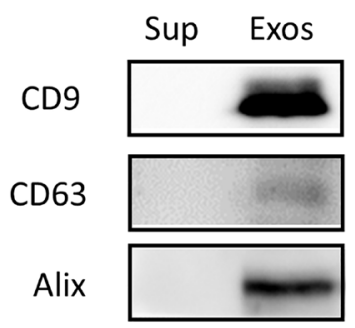

tested (Figure 2A). Importantly, compared to naïve hCECExo, hCEC-Exo-214 further significantly reduced cancer cell viability (Figure 2A). In contrast, naïve hCEC-Exo or hCEC-Exo-214, in combination with oxaliplatin and sorafenib, did not significantly affect normal liver epithelial cell viability (Supplementary Figure 2), suggesting that the enhanced anti-cancer drug activity of combination treatment is specific to HCC tumor cells.

Next, the effect of combination therapy on HCC cell invasion was evaluated by means of a transwell cell

\section{B}

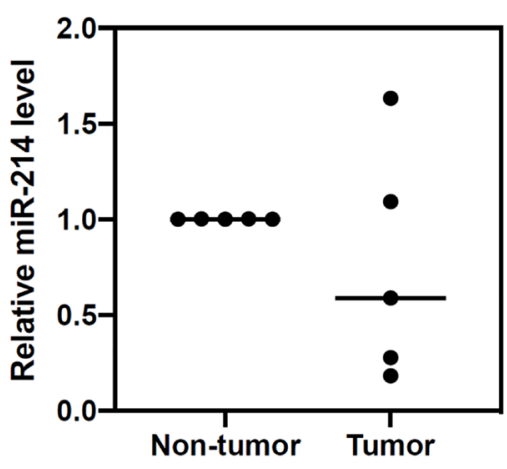

D
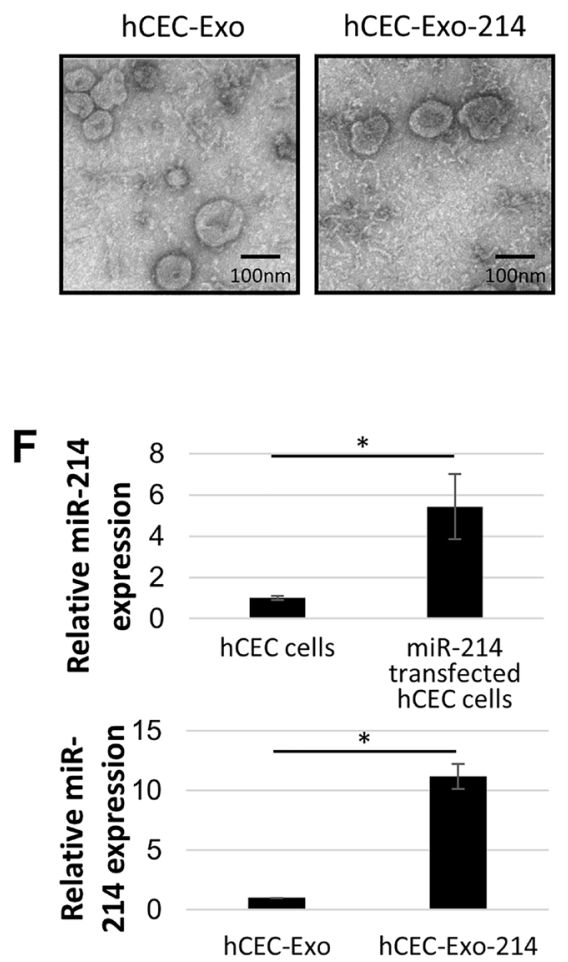

Figure 1: Characterization of miR-214 enriched exosomes. (A) Quantitative RT-PCR analysis of miR-214 and miR-92 levels in cell lines. (B) Quantitative RT-PCR analysis of miR-214 levels in tumor and non-tumor tissue of five individual HCC patients. (C) NTA analysis shows particle distributions of EVs isolated from culture medium of hCEC cells transfected by miR-214. (D) Representative TEM images of exosomes isolated from naïve (hCEC-Exo) and miR-214 transfected (hCEC-Exo-214) hCEC cells. (E) Representative Western blot images show exosomal marker proteins in supernatant (Sup) and exosomes (Exos). (F) Quantitative RT-PCR analysis shows miR-214 levels in non-transfected and transfected hCECs, and in exosomes isolated from naïve (hCEC-Exo) and miR-214 transfected (hCECExo-214) hCEC cells. All mRNAs were normalized with U6 snRNA. Data are presented as mean \pm SEM. $N=3 .{ }^{\sharp} P<0.05,{ }^{\S} P<0.01,{ }^{*} P$ $<0.001$. 
invasion assay $[50,51]$. The transwell assay analysis showed that neither naïve hCEC-Exo nor hCEC-Exo-214 alone significantly reduced cell invasion. However, naïve hCEC-Exo or hCEC-Exo-214, in combination with oxaliplatin or sorafenib significantly reduced HepG2 and Hep3B cell invasion (Figure 2B). Compared with naïve hCEC-Exo, hCEC-Exo-214, in combination with oxaliplatin or sorafenib, had a more robust effect on reduction of HepG2 and Hep3B cell invasion (Figure 2B).

Collectively, these data indicate that hCEC-Exo enhance the anti-HCC effect of oxaliplatin and sorafenib, and that engineered hCEC-Exo-214 have a more potent anti-HCC effect than naïve hCEC-Exo.

\section{Engineered hCEC-Exo-214 sensitize patient tumor-derived primary cells to anti-cancer drugs}

The effect of hCEC-Exo-214, in combination with oxaliplatin or sorafenib, was evaluated in six patientderived tumor cells. Patient 1 had a hepatocellular adenoma (HCA) which is a benign liver tumor. Patients 2-6 had HCC. Compared to anti-cancer drugs alone, naïve hCEC-Exo or hCEC-Exo-214, in combination with oxaliplatin or sorafenib, significantly reduced the viability of patient-derived tumor cells from all three individual patients with HCC (patients 2-4) tested. hCEC-Exo-214 were significantly more effective than naïve hCEC-Exo in sensitizing $\mathrm{HCC}$ to anti-tumor drugs (Figure 3A). Sorafenib is the FDA approved, first-line treatment for advanced hepatocellular carcinoma. We thus, examined the effect of hCEC-Exo-214 in combination with sorafenib on cell invasion of patient tumor-derived primary cells. The combination treatment significantly inhibited primary cell invasion compared with sorafenib treatment alone (Figure 3B). Interestingly, the significant effects of the combination treatment on cell viability and invasion were not detected in primary tumor cells from the patient with HCA (Figure 3A and 3B).

These data suggest that the results of the combination treatment on HepG2 and Hep3B cell lines are more applicable to patient-derived tumor cells from HCC patients than from the HCA patient.

\section{Priming with hCEC-214-Exo sensitizes HCC cells to the anti-tumor effect of therapeutic drugs}

Tumor cell-derived exosomes are essential to metastatic niche formation, tumor development and progression [52]. Although aforementioned data indicate that the hCEC-Exo-214 alone did not impact HCC cell viability and invasion, we examined whether priming $\mathrm{HCC}$ cells with exosomes affects anti-cancer drug efficacy in HCC cells. HepG2 and Hep3B cells were treated with hCEC-Exo-214 for two days, after which culture medium was replaced with fresh medium without hCEC-Exo-214. Oxaliplatin or sorafenib were subsequently applied to the exosome-primed cells. Compared to non-primed HCC cells, oxaliplatin or sorafenib significantly reduced cell viability of HepG2 and Hep3B cells primed with hCECExo-214, although the reduction was marginal (Figure 4A). Considering that cell viability was assayed 6 days after hCEC-Exo-214 priming, the marginal yet significant difference observed (Figure 4A) is of note. However, oxaliplatin or sorafenib more profoundly reduced HepG2 and Hep3B cell invasion in hCEC-Exo-214 primed HCC cells (Figure 4B). Collectively, these priming data suggest that priming HCC cells with hCEC-Exo-214 enhances the anti-cancer drug efficacy of oxaliplatin and sorafenib.

\section{The combination of hCEC-Exo-214 with anti-cancer therapy reduces protein levels of P-glycoprotein and splicing factor $3 B$ subunit 3 in $\mathrm{HCC}$ cells}

P-glycoprotein (P-gp), encoded by the adenosine triphosphate (ATP)-binding cassette subfamily $\mathrm{B}$ member 1 (ABCB1) gene, is one of the genes known to facilitate HCC chemoresistance [27]. Western blot analysis revealed that, compared to drug alone, hCEC-Exo-214 in combination with oxaliplatin or sorafenib significantly reduced P-gp protein levels in HepG2 and Hep3B cells (Figure 5A). The effect of the combination treatment on reduction of P-gp appears specific because the combination treatment did not affect levels of multidrug resistance-associated protein 2 (MRP2) (Supplementary Figure 3). Additionally, we found that hCEC-Exo-214 in combination with oxaliplatin or sorafenib significantly reduced protein levels of splicing factor $3 \mathrm{~B}$ subunit 3 (SF3B3) (Figure 5B). SF3B3 is a putative target for miR214 as predicted by TargetScan (version 7.2, http://www. targetscan.org) (Figure 5C). To verify whether miR-214 targets SF3B3, a dual-luciferase assay was performed. Co-transfection with the wildtype (WT) 3'-UTR region of SF3B3 with miR-214 mimics significantly reduced luciferase activity to $\sim 71.5 \%$ of that seen with a negative control (NC). This is comparable to reduced levels of other genes targeted by miR-214 [14, 15, 17]. In addition, miR-214 mimics did not significantly reduce luciferase activity when SF3B3 3'-UTR was mutated (Figure 5C). These data suggest that miR-214 targets SF3B3 3'-UTR. Collectively, these data suggest that reduction of P-gp and SF3B3 proteins may contribute to the observed beneficial effect of combination treatment on HepG2 and Hep3B cells.

\section{DISCUSSION}

The present study shows that naïve hCEC-Exo and engineered hCEC-Exo-214 substantially sensitize HCC cells to the effects of traditional anti-cancer agents. The impact was significantly more potent with hCECExo-214 than with hCEC-Exo. The effect was seen on 
both HCC cell viability and invasion (Figure 2). The amplified benefit of the combination therapy was observed in multiple HCC cell lines and was also seen in primary cancer cells from multiple patients with HCC. The effect was present with two drugs with divergent mechanisms of action and was specific to neoplastic tissue. These in vitro data demonstrate, for the first time, that hCEC-Exo, particularly exosomes carrying elevated miR-214, can enhance the anti-tumor effect of oxaliplatin or sorafenib against HCC.

Tumor-derived extracellular vesicles (EVs), including exosomes, mediate cancer formation, progression, and metastasis by facilitating communication between the cancer niche and distal cells [53]. For example, tumor-derived exosomes induce epithelialmesenchymal transition (EMT) [54] and chemoresistance $[55,56]$. Compared to studies using tumor-derived EVs as biomarkers of cancer presence or progression, investigations of exogenous exosomes as therapeutic agents in cancer are more limited. EVs derived from human liver stem cells suppress growth of HepG2 and primary HCC cells [57], while EVs derived from human bone marrow mesenchymal stem cells inhibit in vitro cell cycle progression of several tumor cell lines, including

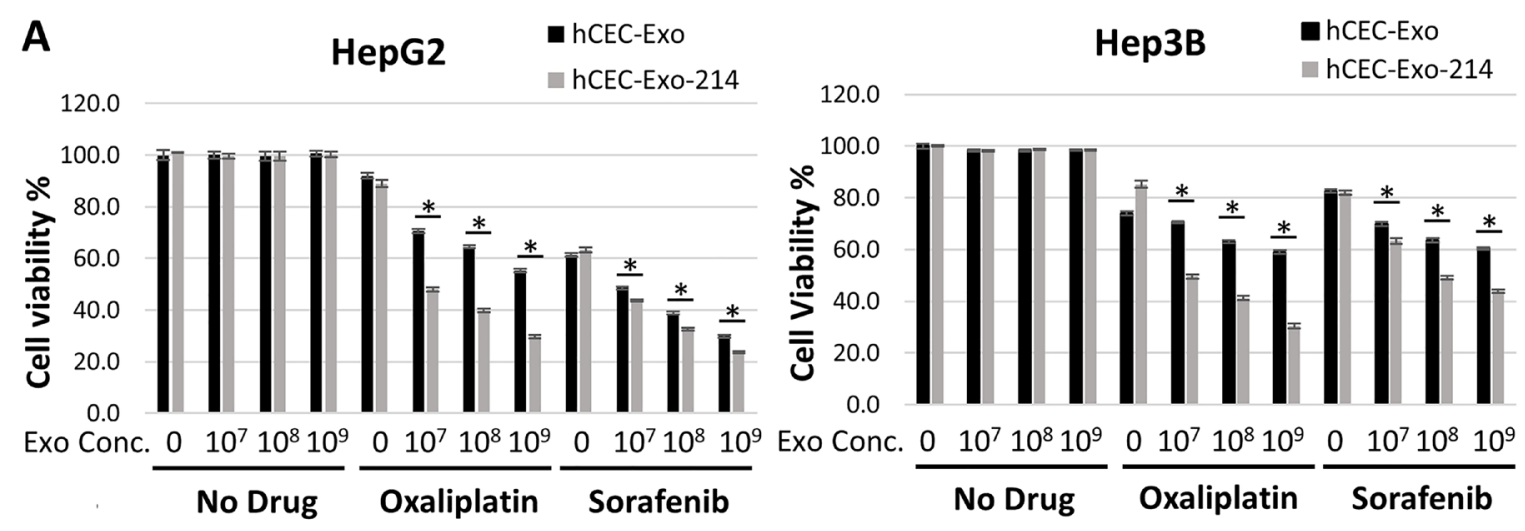

B
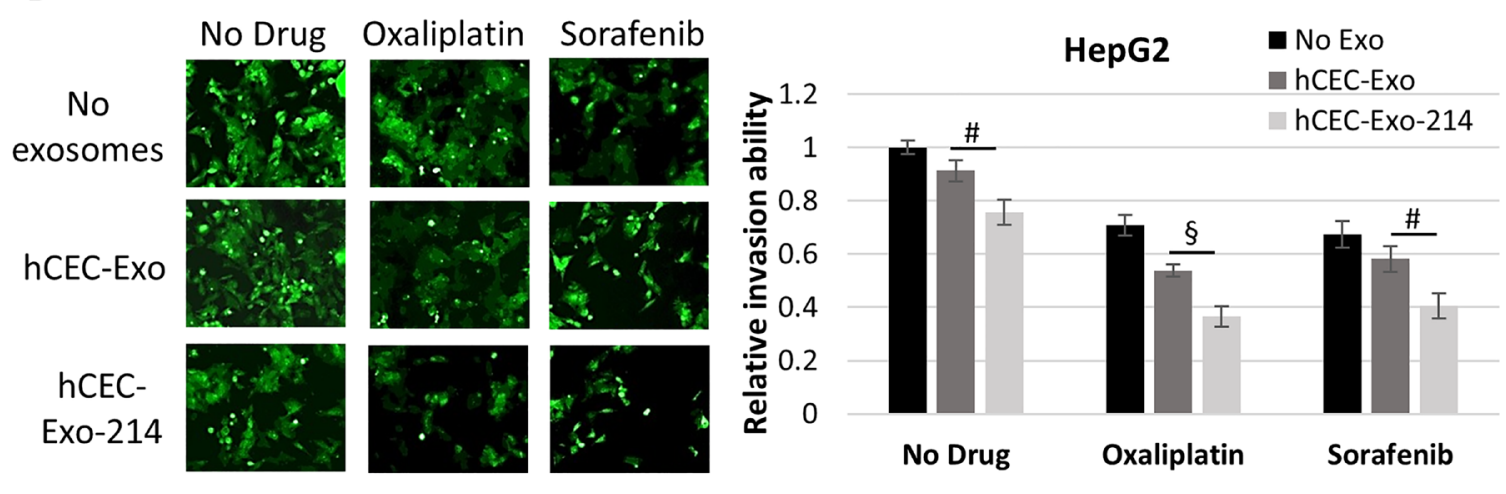

C
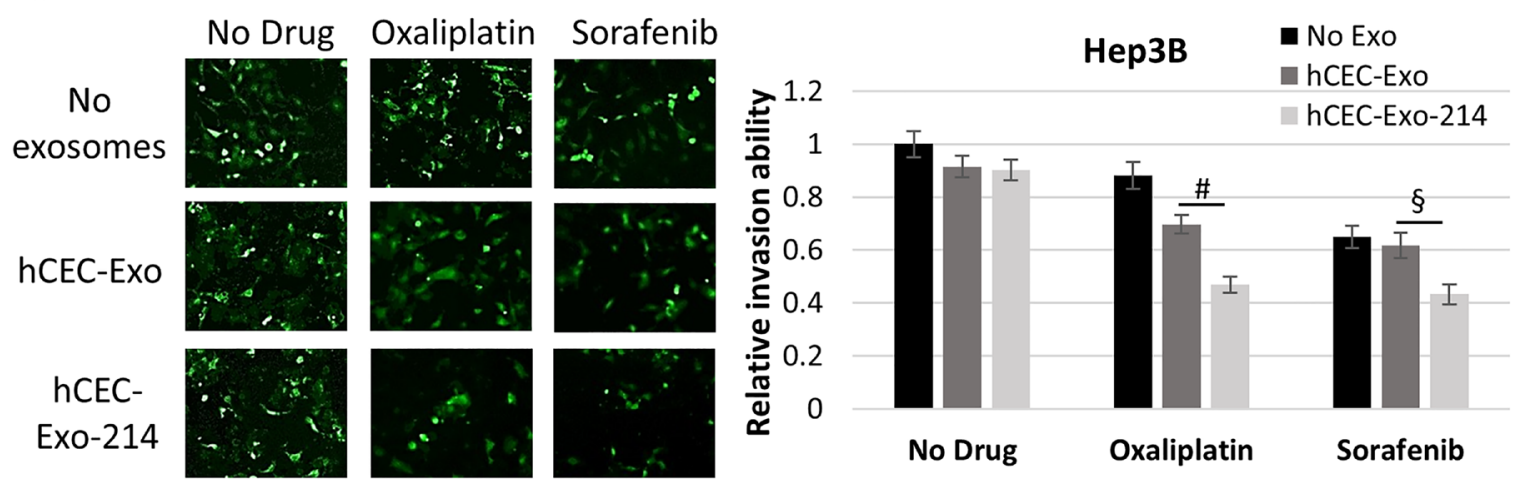

Figure 2: hCEC-Exo-214 sensitize HCC cells to anti-cancer drugs. (A) Cell viability of HepG2 and Hep3B cells treated with anti-cancer drugs and exosomes. Data are representative of three independent experiments. Values are expressed as mean \pm SD. $N=5$. (B and C) Representative images and quantitative data show cell invasion of HepG2 (B) and Hep3B (C) cells treated with hCEC-Exo or hCEC-Exo-214 in combination with oxaliplatin or sorafenib. Data are presented as mean \pm SEM. $N=3 .{ }^{\#} P<0.05,{ }^{\S} P<0.01,{ }^{*} P<0.001$. 
HepG2, and in vivo progression of subcutaneous tumors in SCID mice [58].

The present study shows that naïve hCEC-Exo and engineered hCEC-Exo-214 sensitize HCC cells to the anticancer effects of sorafenib and oxaliplatin as measured by cell viability and invasion assays (Figures 2 and 3 ). These findings are further supported by priming data in which HCC cells, pre-treated with naïve hCEC-Exo or engineered hCEC-Exo-214, experience an enhanced antitumor effect of oxaliplatin or sorafenib. Monotherapy with naïve hCEC-Exo or engineered hCEC-Exo-214 did not significantly affect HCC cell viability or invasion
(Figure 4). The therapeutic effect is specific to HepG2 and Hep3B cells in that the combination therapy did not affect the viability or invasion of the hepato-epithelial cell line, THLE-2 (Supplementary Figure 2). Importantly, the anti-tumor effect of the combination therapy was observed in primary cancer cells derived from patients with HCC but not in tumor cells derived from a patient with HCA (Figure 3). These data suggest that the combination therapy preferentially targets $\mathrm{HCC}$ cells, which is consistent with evidence that the interaction of exosome cargo with recipient cells is cell type dependent [59]. Taken together, the present study suggests a potential therapeutic role for

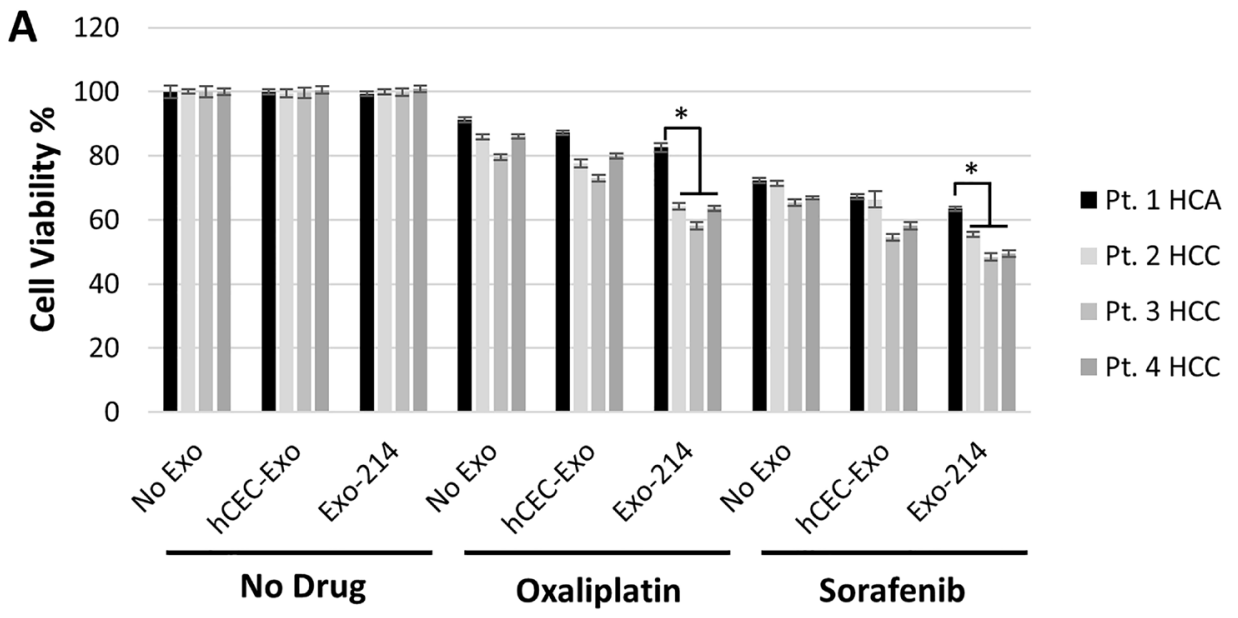

B
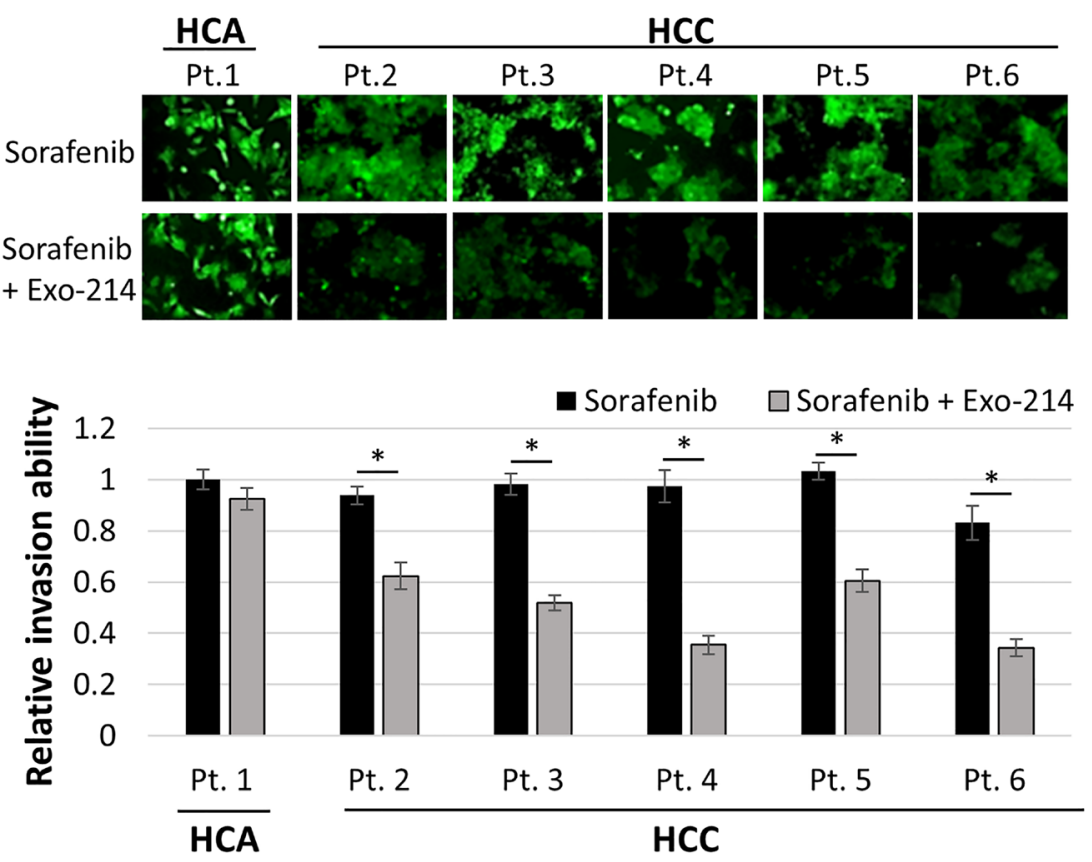

Figure 3: The effect of the combination therapy on tumor primary cells derived from patients with liver tumor. (A) Quantitative data from MTT assay showed the effect of hCEC-Exo or hCEC-Exo-214 in combination with oxaliplatin or sorafenib on cell viability of primary cells derived from tumor tissues of four individual patients (Pt) with hepatocellular adenoma (HCA) or hepatocellular adenoma (HCC). Data are presented as mean \pm SD. $N=5$. (B) Representative microscopic images and quantitative invasion data showed the effect of hCEC-Exo or hCEC-Exo-214 in combination with sorafenib on cell invasion of primary cells derived from tumor tissues of six individual patients with HCA or HCC. Values are expressed in mean \pm SEM. $N=3 .{ }^{*} P<0.001$. 
exosomes derived from human cerebral endothelial cells to enhance traditional anti-cancer drug treatment in HCC.

The use of exosomes to deliver miRNAs for treatment of HCC has been investigated. Exosomes carrying miR-451a [41], miR-125b [42], miR-122 [43] and miR-26 [40] suppress HCC growth. However, the role of miR-214 in mediating cancer progression has been investigated with inconsistent results. In one study, miR-214 was found to have increased expression in breast cancer tissue which contributed to cell invasion $[60,61]$. A conflicting study found decreased levels of miR-214 in breast cancer tissue leading to increased cell proliferation and invasion $[60,61]$. In addition, miR-214 negatively regulates liver metastasis of colorectal cancer [18], but contributes to tumor progression and metastasis in melanoma [62]. In HCC, overexpression of miR-214 in HepG2, Hep3B, HLE, and SK-HEP-1 cells suppresses cell growth and invasion [14, 19]. Ectopic expression of miR-214 in SK-HEP-1 cells inhibits xenograft tumor formation and decreases microvascular density in tumorbearing nude mice [14]. In this study, using qRT-PCR analysis, miR-214 was found to be downregulated in $\mathrm{HCC}$ cell lines and in primary patient HCC cells, which validates reports by others [14-16]. Using multiple experimental approaches, the present study, for the first time, demonstrates that exosomes carrying elevated miR214 enhance anti-cancer drug sensitivity in HCC cells.

Therapeutically engineered exosomes carrying elevated miR-214, hCEC-Exo-214, robustly and specifically amplify anti-cancer drug efficacy in HCC cell lines and in patient-derived HCC cells. We do not rule out that exosomes from other cells may have comparable activity, in this regard, but we chose to evaluate hCECExo because we found, in preliminary studies, they

A
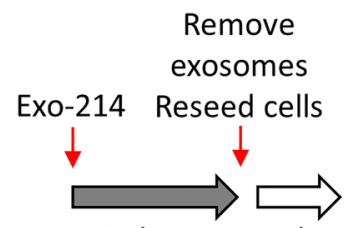

Anti-cancer

2 days

1 day
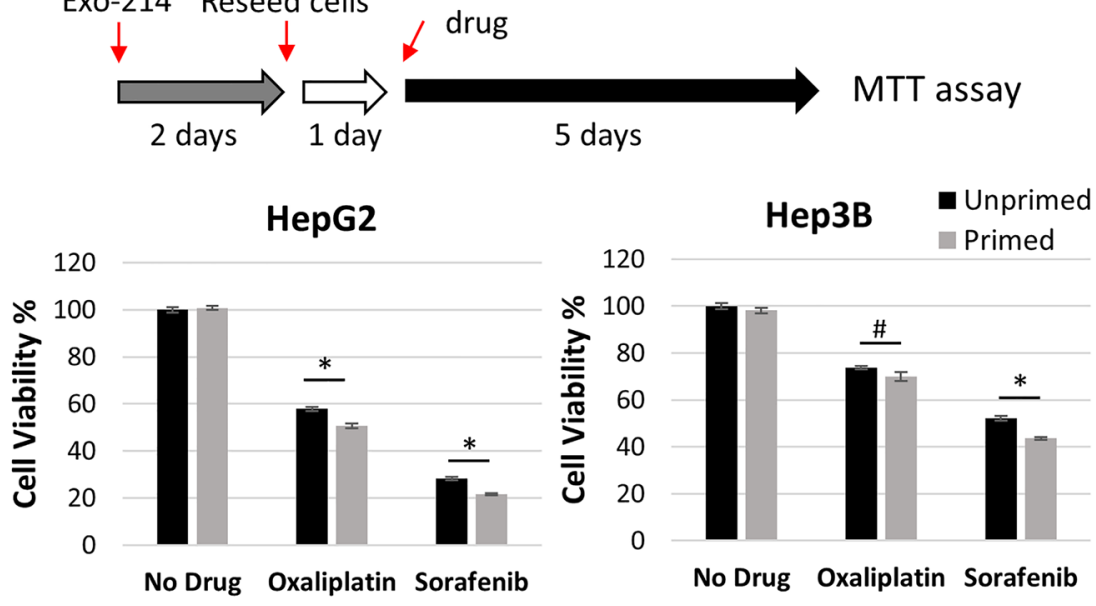

B

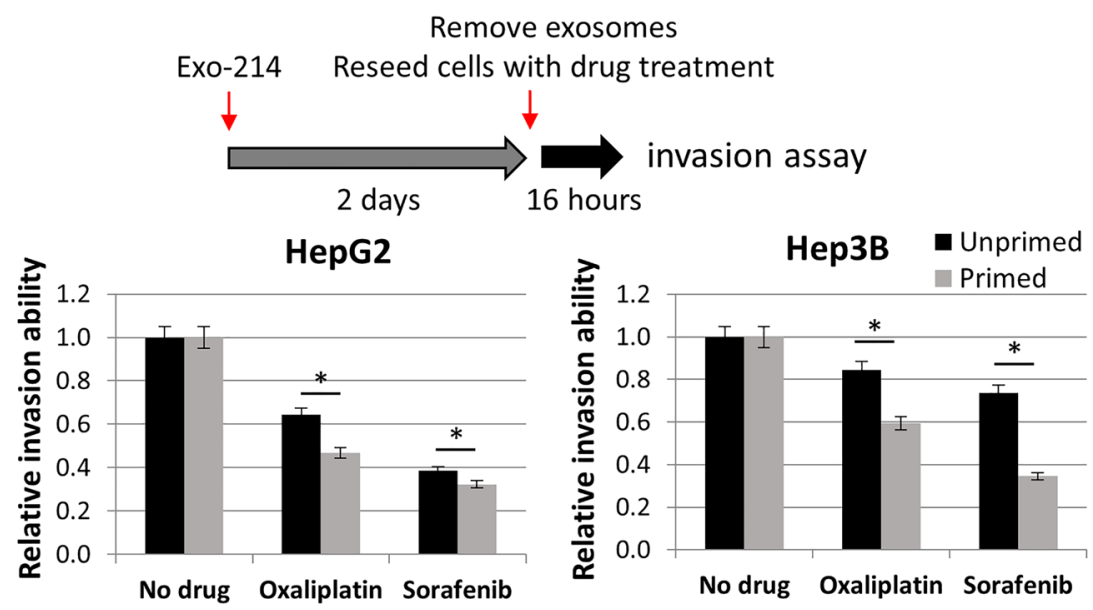

Figure 4: The effect of priming HCC cells with hCEC-Exo-214 on anti-cancer drug treatment. (A) Schematic illustration of priming experimental protocol of cell viability and quantitative data of cell viability of primed HepG2 and Hep3B cells. Data are presented as mean \pm SD. $N=5$. (B) Schematic illustration of priming experimental protocol of cell invasion and quantitative data of cell invasion of primed HepG2 and Hep3B cells. Values are expressed in mean \pm SEM. $N=3 .{ }^{*} P<0.05,{ }^{*} P<0.001$. 
were superior to mesenchymal stem cell exosomes in mitigating chemotherapy induced neurotoxicity and in enhancing antineoplastic drug activity (data not shown). Although miRNA-214 has been shown to target p53 in breast cancer [60], this is not likely the mechanism by which hCEC-Exo-214 exert their effect in HCC. hCECExo-214 significantly increased anti-cancer drug activity in both HepG2 and Hep3B cell lines. However, HepG2 cells are p53 wildtype allele, whereas Hep3B cells are p53 null allele [63]. Instead, this study suggests that hCECExo-214 target P-gp and SF3B3. Western blot analysis showed significant reduction in protein levels of both
P-gp and SF3B3, two genes directly or indirectly targeted by miR-214 (Figure 5). Both genes have been reported to be involved in cancer progression. P-gp mediates chemoresistance in HCC $[27,64]$. Increased expression of P-gp was observed in HCC cells resistant to 5-fluorouracil and epirubicin, as well as sorafenib $[65,66]$. Reducing P-gp using antisense RNA attenuates doxorubicin resistance in HepG2 cells [67], whereas increased P-gp levels substantially reduces sorafenib efficacy in HCC cells [68]. SF3B3 is a pro-oncogene in renal cancer and knockdown of SF3B3 in renal cancer cells significantly inhibits tumor growth in tumor-bearing mice [69]. SF3B3
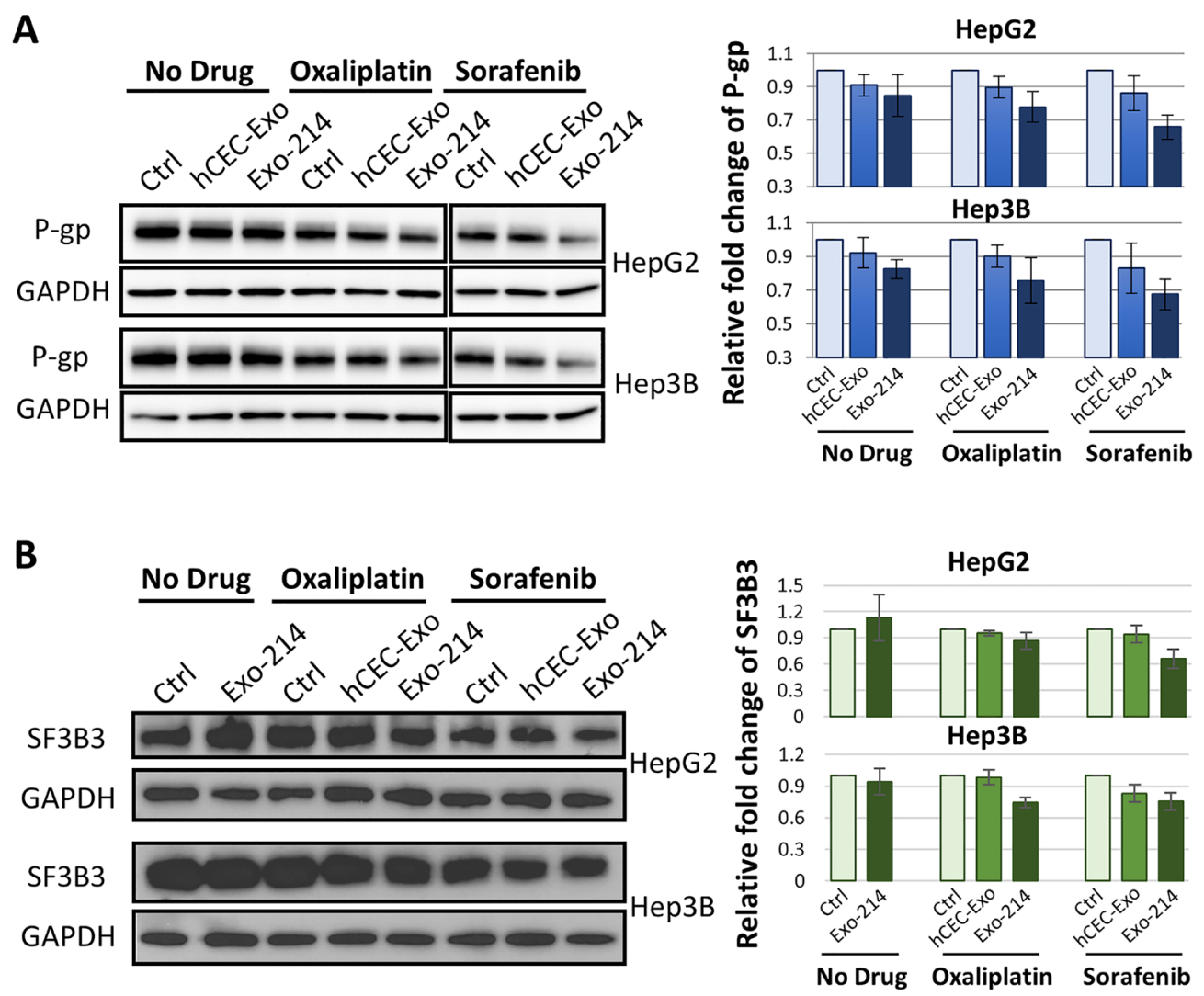

C

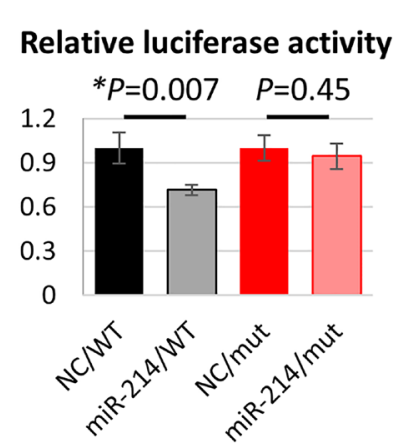

Figure 5: The effect of hCEC-Exo-214 in combination with anti-cancer drugs on P-gp and SF3B3 in HCC cells. (A and B) Representative Western blot images and quantitative data of protein levels of P-gp (A) and SF3B3 (B) in HepG2 and Hep3B cells 2 days after treatment. Blot images of sorafenib treatment set were combined with no drug and oxaliplatin treatment set. Western blot band intensity was quantified by using ImageJ with normalization to GAPDH. Values are expressed in mean \pm SEM. $N=3$. (C) Dual-luciferase activity assay. Putative miR-214-3p target sequence of SF3B3 3'-UTR region were listed. WT: wildtype. mut: mutant. Assay was performed in HepG2 cells. NC: negative control. Values are normalized and are presented in mean $\pm \mathrm{SEM} . N=3$ individual experiments. 
also regulates enhancer of zeste 2 polycomb repressive complex 2 subunit (EZH2) that promotes HCC progression $[70,71] . \mathrm{EZH} 2$ is one of the genes directly targeted by miR-214 and overexpression of miR-214 reduces EZH2 protein levels [14]. Thus, reduction of P-gp and SF3B3 by hCEC-Exo-214 is likely to amplify the effect of anticancer drugs on HCC cells. Clearly a single miRNA targets numerous mRNAs and an individual mRNA can be targeted by several miRNAs $[12,72]$. In addition to miR214, exosomal cargo contains other miRNAs, proteins and lipids and their roles in mediating the therapeutic effects of the combination therapy cannot be excluded and warrant further investigation.

In summary, our data demonstrate that engineered hCEC-Exo-214 significantly enhance the efficacy of oxaliplatin and sorafenib anti-cancer drugs in HCC. The findings support a potential clinical strategy of combining engineered hCEC-derived exosomes with anti-cancer agents to improve medical therapy in HCC.

\section{MATERIALS AND METHODS}

\section{Patients and tissues}

Patient tissues used in the present study were obtained from patients with hepatocellular carcinoma or hepatocellular adenoma who underwent liver resection or liver transplant at Henry Ford Hospital (Detroit, MI, USA). The study was approved by the Henry Ford Health System (HFHS) Institutional Review Board (IRB No.12996). The IRB grants a waiver of the requirements to obtain informed consent. All experiments were performed in accordance with relevant guidelines and regulations.

\section{Anti-cancer drugs}

Oxaliplatin was purchased from Sigma \& Aldrich (St. Louis, MO, USA) and was dissolved in dimethyl sulfoxide (DMSO) to make stock solution at $25 \mathrm{mM}$. Sorafenib was purchased from Santa Cruz Biotechnology (Dallas, TX, USA), and was dissolved in dimethyl sulfoxide (DMSO) to make stock solution at $100 \mathrm{mM}$. The stock solutions were further diluted to appropriate concentrations with cell culture medium immediately prior to experiments. DMSO was used as a control.

\section{Cell culture}

Hepatocellular carcinoma cell lines HepG2 (ATCC ${ }^{\circledR}$ HB-8065 ${ }^{\mathrm{TM}}$ ), Hep3B (ATCC ${ }^{\circledR} \mathrm{HB}-8064^{\mathrm{TM}}$ ), and the human liver epithelial cell line THLE-2 (ATCC ${ }^{\circledR}$ CRL$2706^{\mathrm{TM}}$ ) were purchased from American Type Culture Collection (ATCC, Rockville, MD) and were cultured in Eagle's Minimum Essential Medium (EMEM; ATCC). All cell lines were maintained in EMEM containing 10\% fetal bovine serum (FBS), 100 units/ml penicillin, $50 \mu \mathrm{g} /$ $\mathrm{ml}$ streptomycin, and $100 \mu \mathrm{g} / \mathrm{ml}$ amphotericin (Invitrogen, Waltham, MA, USA). Cell cultures were maintained in 75 $\mathrm{cm}^{2}$ flasks and kept in a humidified atmosphere with 5\% $\mathrm{CO}_{2}$ at $37^{\circ} \mathrm{C}$.

Primary human cerebral endothelial cells (hCEC) (Primary Human Brain Microvascular Endothelial Cells ACBRI 376) were purchased from Cell Systems. The cell culture was maintained using Cell System complete classic medium (4Z0-500) with CultureBoost according to the manufacturer's protocol.

Liver tumor and adjacent non-tumor tissues were acquired from patients with $\mathrm{HCC}$ and liver tumor undergoing liver resection or transplant and the collected tissues were kept in Eagle's Minimum Essential Medium (EMEM) at $4^{\circ} \mathrm{C}$. Under aseptic conditions, the connective tissues, bile ducts, and blood vessels were trimmed away as much as possible. Tumor tissues were then minced into approximate $1 \mathrm{~mm}$ pieces and incubated in 6-well plates coated with attachment factor (Cell Systems: 4Z0-210) in EMEM medium 10\% fetal bovine serum (FBS) and 1\% of anti-anti (Invitrogen). Plates were kept in a humidified atmosphere with $5 \% \mathrm{CO}_{2}$ at $37^{\circ} \mathrm{C}$ for $2-3$ days to allow attachment. Media was changed regularly, and cells were passed at $80-90 \%$ confluency. All experiments were done within 5-10 cell passages.

\section{Transfection of miR-214 into hCEC cells}

The human pre-microRNA expression construct Lenti-miR-214 (PMIRH214PA-1) was purchased from System Biosciences. Briefly, $5 \times 10^{5}$ hCECs were suspended in $100 \mu \mathrm{l}$ of Ingenio Electroporation Solution (Mirus Bio LLC., Madison, WI, USA) with $3 \mu \mathrm{g}$ of plasmid DNA. Program U11 was used for electroporation in an Amaxa Nucleofector Device (Lonza Group Ltd., Walkersville, MD, USA). Transfected hCECs were resuspended in $10 \mathrm{ml}$ complete culture medium, followed by centrifugation at $500 \times \mathrm{g}$, and then cultured for exosome production. $1 \times 10^{6} \mathrm{hCECs}$ were seeded in $10 \mathrm{ml}$ complete classic medium (4Z0-500, Cell Systems, Kirkland, WA, USA) and cultured for $48 \mathrm{hr}$. The culture medium was then replaced with serum free medium (4Z3-500, Cell Systems, Kirkland, WA, USA), and cells were cultured for an additional $48 \mathrm{hr}$ when engineered exosomes were collected for analysis and experiments.

\section{Isolation and characterization of exosomes from naïve and engineered hCECs}

Exosomes derived from hCECs or miR-214 transfected hCECs were isolated from the supernatant of CECs cultured in exosome free medium according to our published protocol [73]. Briefly, the culture medium of hCECs was collected after a 48 72 h incubation period according to time required to reach $80 \%$ confluence, followed by centrifugation at 2,000 rpm for $5 \mathrm{~min}$. The supernatant of the spin down was filtered through $0.22 \mu \mathrm{m}$ 
filter (Millipore, CA, USA) to remove dead and large cell debris. The flow through was then centrifuged at $100,000 \mathrm{Xg}$ for 2 hours. The pellet was dissolved in $200 \mu \mathrm{l}$ sterilized PBS, and the supernatant was collected as a negative control. The particle numbers and size of harvested hCEC-exosomes were analyzed by Nanoparticle Tracking Analysis (NTA) system (IZON, UK). Transmission electron microscope (TEM) and Western blot analysis were performed to characterize hCEC-exosomes [74]. Total proteins from hCEC-exosomes were collected using $2 \mathrm{X}$ lysis buffer (RIPA, Sigma) supplemented with Protease Inhibitor Cocktails set I (100X) (MilliporeSigma, Burlington, MA, USA) followed by Western Blot analysis of exosomal marker proteins.

\section{MTT (3-(4,5-dimethylthiazol-2-yl)-2,5 diplenyltetrazolium bromide) assay}

To measure cell viability, cells were seeded in 96-well plates at a density of 800 cells per well. After overnight incubation, culture medium was removed, and cells were rinsed with PBS and incubated in complete medium with indicated treatment. After 5 days of treatment, medium was removed and MTT was added to each well with an additional $4 \mathrm{hr}$ incubation to allow mitochondrial dehydrogenase to convert MTT into insoluble formazan crystals. The medium was then aspirated, and formazan solubilized by adding $150 \mu \mathrm{l}$ of DMSO. The absorption of solubilized formazan was measured at a wavelength of 490 $\mathrm{nm}$ by an ELISA plate reader (EL340 microplate reader; Bio-Tek Instruments, Winooske, VT, USA).

\section{Invasion assay}

Invasion assay was performed according to our published protocol with modification [75]. Specifically, 24-well Plate invasion chambers were pre-coated with Matrigel (Corning, Corning, NY, USA). HepG2 or Hep3B cells $\left(5 \times 10^{4}\right)$, after receiving indicated treatment for 2 days, were re-suspended in $0.5 \mathrm{ml}$ of serumfree medium and loaded to the upper chamber while the lower chamber was filled with $0.5 \mathrm{ml}$ of complete medium containing FBS, which served as a chemoattractant. After $16 \mathrm{hr}$ of incubation at $37^{\circ} \mathrm{C}$, cell ability to penetrate the extracellular matrix $(\mathrm{ECM})$ was assessed by staining the cells on the lower surface of the membrane with CellTracker ${ }^{\mathrm{TM}}$ Green (Molecular Probes, Eugene, OR, USA). Four fields of cells were counted randomly in each well under a fluorescent microscope at $200 \times$ magnification. Data are normalized to control treatment, which is set as 1 , and are expressed as mean \pm SEM of three independent experiments.

\section{Western blot analysis}

HepG2 and Hep3B cells $\left(5 \times 10^{5}\right.$ cells $)$ were seeded in T25 flasks. One day after seeding, cells were subjected to indicated treatment for $48 \mathrm{hr}$. Cells were rinsed with ice cold PBS followed by extraction in $500 \mu$ R RIPA lysis buffer (Life Technologies, Carlsbad, CA, USA). Equal amounts of proteins, as determined by the BCA protocol (Pierce, Rockford, IL, USA), were run on $10 \%$ TrisGlycine gels (Invitrogen) and then transferred to PVDF membranes (Whatman). The membranes were blocked with $0.1 \%$ I-Block (Applied Biosystems, Foster, CA, USA) in PBS-T (0.1\% Tween-20), followed by incubation with primary antibodies against P-gp (ab170904, Abcam), MRP2 (R260, Cell Signaling), SF3B3 (ab209402, Abcam), GAPDH (ab9484, Abcam), CD9 (ab92726, Abcam), CD63 (ab134045, Abcam), and Alix (3A9, Cell Signaling). Bands were detected using SuperSignal West Pico chemiluminescent protein detection kits (Pierce). Each experiment was repeated three times. The densities of the bands were analyzed using ImageJ software.

\section{Isolation of total RNA and quantitative reverse transcribed-PCR}

After 2 days of treatment, HepG2 and Hep3B cells were lysed in Qiazol reagent, and the total RNA was isolated using miRNeasy Mini kits (Qiagen, Valencia, CA, USA). miRNA was stem-loop reverse transcribed (RT) with the miRNA Reverse Transcription kit (Applied Biosystems) and real-time PCR amplification was performed with the TaqMan miRNA assay (Cat\# 4427975, Applied Biosystems), which is specific for mature miRNA sequences. U6 snRNA was used as the internal control for TaqMan miRNA assay to detect the expression level changes of miR-214 in cells. Primers used for miR-214-3p (Assay ID: 002306), miR-92-3p (Assay ID: 000431), U6 (Assay ID: 001973).

\section{Dual-luciferase activity assay}

Luciferase reporter assay was conducted according to previous report [76]. Briefly, HepG2 cells were cultured in 6-well plates and co-transfected with $3 \mu \mathrm{mol}$ of pMIRREPORT (Applied Biosystems) containing either SF3B33'UTR-WT or SF3B3-3'UTR-mut, 30 pmol of miR-214-3p mimics (Cat\#:4464066. ThermoFisher Scientific, Waltham, MA) or negative control (Cat\#:4464058), and $1 \mu \mathrm{mol}$ of pRL-TK (Promega, Madison, WI, USA) containing Renilla luciferase per well. Transfection was performed by means of Lipofectamine 2000 (Invitrogen) and OptiMEM I reduced serum medium (Invitrogen). Three days after transfection, firefly and Renilla luciferase activity was analyzed by using the Dual-Luciferase Reporter Assay kit (Promega) and plate reader (Perkin Elmer, Waltham, MA, USA). Data were presented as relative luciferase activity. Three independent experiments were performed.

\section{Statistical analysis}

Data are presented as mean and standard error. Statistical significance was analyzed by Student $T$-test. $P$ value less than $0.05(P<0.05)$ was considered significant. 


\section{Abbreviations}

HCC: hepatocellular carcinoma; HCA: hepatocellular adenoma; hCEC: human cerebral endothelial cells; Exos: exosomes; Sup: supernatant; hCEC-Exo: hCEC-derived exosomes; hCEC-Exo-214: engineered hCEC-derived exosomes carrying elevated miR-214; P-gp: P-glycoprotein; SF3B3: splicing factor 3B subunit 3; Pt.: patient.

\section{Author contributions}

Q.Z., Y.L., D.M., and Z.G.Z., designed the study. L.S., Q.Z., Y.L., Y.Z., M.M.Z., and M.B.C. performed the experiments and analyzed the data. Q.Z. and Z.G.Z. wrote the manuscript. D.M. and M.C. critically revised the manuscript. All authors approved the manuscript.

\section{CONFLICTS OF INTEREST}

Z.G.Z., M.C., Y.Z., Y.L., and D.M. are inventors on a US patent application submitted by Henry Ford Hospital, that covers methods to enhance chemotherapy by the exosomes. Remaining authors have no competing interest.

\section{FUNDING}

This work was partly supported by Henry Ford Cancer Institute post-doctoral fellowship program funding towards Q.Z.

\section{REFERENCES}

1. Li X, Li C, Zhang L, Wu M, Cao K, Jiang F, Chen D, Li N, $\mathrm{Li} \mathrm{W}$. The significance of exosomes in the development and treatment of hepatocellular carcinoma. Mol Cancer. 2020; 19:1. https://doi.org/10.1186/s12943-019-1085-0. [PubMed]

2. Medavaram S, Zhang Y. Emerging therapies in advanced hepatocellular carcinoma. Exp Hematol Oncol. 2018; 7:17. https://doi.org/10.1186/s40164-018-0109-6. [PubMed]

3. Cheng AL, Kang YK, Chen Z, Tsao CJ, Qin S, Kim JS, Luo R, Feng J, Ye S, Yang TS, Xu J, Sun Y, Liang H, et al. Efficacy and safety of sorafenib in patients in the AsiaPacific region with advanced hepatocellular carcinoma: a phase III randomised, double-blind, placebo-controlled trial. Lancet Oncol. 2009; 10:25-34. https://doi.org/10.1016/ S1470-2045(08)70285-7. [PubMed]

4. Anwanwan D, Singh SK, Singh S, Saikam V, Singh R. Challenges in liver cancer and possible treatment approaches. Biochim Biophys Acta Rev Cancer. 2020; 1873:188314. https://doi.org/10.1016/j.bbcan.2019.188314. [PubMed]

5. Colagrande S, Inghilesi AL, Aburas S, Taliani GG, Nardi C, Marra F. Challenges of advanced hepatocellular carcinoma. World J Gastroenterol. 2016; 22:7645-59. https://doi. org/10.3748/wig.v22.i34.7645. [PubMed]
6. Gebert LFR, MacRae IJ. Regulation of microRNA function in animals. Nat Rev Mol Cell Biol. 2019; 20:21-37. https:// doi.org/10.1038/s41580-018-0045-7. [마Med]

7. Lagos-Quintana M, Rauhut R, Lendeckel W, Tuschl T. Identification of novel genes coding for small expressed RNAs. Science. 2001; 294:853-8. https://doi.org/10.1126/ science.1064921. [PubMed]

8. Xu X, Tao Y, Shan L, Chen R, Jiang H, Qian Z, Cai F, Ma L, Yu Y. The Role of MicroRNAs in Hepatocellular Carcinoma. J Cancer. 2018; 9:3557-69. https://doi. org/10.7150/jca.26350. [PubMed]

9. Tricoli L, Niture S, Chimeh U, Kumar D. Role of microRNAs in the development of hepatocellular carcinoma and acquired drug resistance. Front Biosci (Landmark Ed). 2019; 24:545-54. [PubMed]

10. Pan JH, Zhou H, Zhao XX, Ding H, Li W, Qin L, Pan YL. Role of exosomes and exosomal microRNAs in hepatocellular carcinoma: Potential in diagnosis and antitumour treatments (Review). Int J Mol Med. 2018; 41:1809-16. https://doi.org/10.3892/ijmm.2018.3383. [PubMed]

11. Vasuri F, Visani M, Acquaviva G, Brand T, Fiorentino M, Pession A, Tallini G, D'Errico A, de Biase D. Role of microRNAs in the main molecular pathways of hepatocellular carcinoma. World J Gastroenterol. 2018; 24:2647-60. https:// doi.org/10.3748/wig.v24.i25.2647. [PubMed]

12. Penna E, Orso F, Taverna D. miR-214 as a key hub that controls cancer networks: small player, multiple functions. J Invest Dermatol. 2015; 135:960-9. https://doi.org/10.1038/ iid.2014.479. [PubMed]

13. Zhang LL, Guo YJ, Zhao CN, Gao JY. Effects and mechanism of miR-214 on hepatocellular carcinoma. Asian Pac J Trop Med. 2015; 8:392-8. https://doi.org/10.1016/ S1995-7645(14)60350-3. [PubMed]

14. Xia H, Ooi LL, Hui KM. MiR-214 targets beta-catenin pathway to suppress invasion, stem-like traits and recurrence of human hepatocellular carcinoma. PLoS One. 2012; 7:e44206. https://doi.org/10.1371/journal. pone.0044206. [PubMed]

15. Li Y, Li Y, Chen Y, Xie Q, Dong N, Gao Y, Deng H, Lu C, Wang S. MicroRNA-214-3p inhibits proliferation and cell cycle progression by targeting MELK in hepatocellular carcinoma and correlates cancer prognosis. Cancer Cell Int. 2017; 17:102. https://doi.org/10.1186/s12935-017-0471-1. [PubMed]

16. Wang P, Chen S, Fang H, Wu X, Chen D, Peng L, Gao Z, Xie C. miR-214/199a/199a* cluster levels predict poor survival in hepatocellular carcinoma through interference with cell-cycle regulators. Oncotarget. 2016; 7:929-45. https://doi.org/10.18632/oncotarget.6137. [PubMed]

17. Shih TC, Tien YJ, Wen CJ, Yeh TS, Yu MC, Huang CH, Lee YS, Yen TC, Hsieh SY. MicroRNA-214 downregulation contributes to tumor angiogenesis by inducing secretion of the hepatoma-derived growth factor in human hepatoma. 
J Hepatol. 2012; 57:584-91. https://doi.org/10.1016/j. jhep.2012.04.031. [PubMed]

18. Chen DL, Wang ZQ, Zeng ZL, Wu WJ, Zhang DS, Luo HY, Wang F, Qiu MZ, Wang DS, Ren C, Wang FH, Chiao LJ, Pelicano H, et al. Identification of microRNA-214 as a negative regulator of colorectal cancer liver metastasis by way of regulation of fibroblast growth factor receptor 1 expression. Hepatology. 2014; 60:598-609. https://doi. org/10.1002/hep.27118. [PubMed]

19. Yang Y, Zhao Z, Hou N, Li Y, Wang X, Wu F, Sun R, Han J, Sun H, Song T, Huang C, Shao Y. MicroRNA214 targets Wnt3a to suppress liver cancer cell proliferation. Mol Med Rep. 2017; 16:6920-7. https://doi.org/10.3892/ mmr.2017.7483. [PubMed]

20. Chen Y, Gao DY, Huang L. In vivo delivery of miRNAs for cancer therapy: challenges and strategies. Adv Drug Deliv Rev. 2015; 81:128-41. https://doi.org/10.1016/j. addr.2014.05.009. [PubMed]

21. Pegtel DM, Gould SJ. Exosomes. Annu Rev Biochem. 2019; 88:487-514. https://doi.org/10.1146/annurevbiochem-013118-111902. [PubMed]

22. Zhang Y, Liu Y, Liu H, Tang WH. Exosomes: biogenesis, biologic function and clinical potential. Cell Biosci. 2019; 9:19. https://doi.org/10.1186/s13578-019-0282-2. [PubMed]

23. Thery C, Boussac M, Veron P, Ricciardi-Castagnoli P, Raposo G, Garin J, Amigorena S. Proteomic analysis of dendritic cell-derived exosomes: a secreted subcellular compartment distinct from apoptotic vesicles. J Immunol. 2001; 166:7309-18. https://doi.org/10.4049/ jimmunol.166.12.7309. [PubMed]

24. Vidal M, Sainte-Marie J, Philippot JR, Bienvenue A. Asymmetric distribution of phospholipids in the membrane of vesicles released during in vitro maturation of guinea pig reticulocytes: evidence precluding a role for "aminophospholipid translocase". J Cell Physiol. 1989; 140:455-62. https://doi. org/10.1002/jcp.1041400308. [PubMed]

25. Valadi H, Ekstrom K, Bossios A, Sjostrand M, Lee JJ, Lotvall JO. Exosome-mediated transfer of mRNAs and microRNAs is a novel mechanism of genetic exchange between cells. Nat Cell Biol. 2007; 9:654-9. https://doi. org/10.1038/ncb1596. [PubMed]

26. Kalluri R, LeBleu VS. The biology, function, and biomedical applications of exosomes. Science. 2020; 367:eaau6977. https://doi.org/10.1126/science.aau6977. [PubMed]

27. Duan B, Huang C, Bai J, Zhang YL, Wang X, Yang J, Li J. (2019). Multidrug Resistance in Hepatocellular Carcinoma. In: Tirnitz-Parker JEE, ed. Hepatocellular Carcinoma. (Brisbane, AU). https://doi.org/10.15586/ hepatocellularcarcinoma.2019.ch8.

28. Tung KH, Ernstoff MS, Allen C, Shu S. A Review of Exosomes and their Role in The Tumor Microenvironment and Host-Tumor "Macroenvironment". J Immunol Sci. 2019; 3:4-8. https://doi.org/10.29245/25783009/2019/1.1165. [PubMed]
29. Huang T, Deng CX. Current Progresses of Exosomes as Cancer Diagnostic and Prognostic Biomarkers. Int J Biol Sci. 2019; 15:1-11. https://doi.org/10.7150/ijbs.27796. [PubMed]

30. Wortzel I, Dror S, Kenific CM, Lyden D. ExosomeMediated Metastasis: Communication from a Distance. Dev Cell. 2019; 49:347-60. https://doi.org/10.1016/j. devcel.2019.04.011. [PubMed]

31. Kalluri R. The biology and function of exosomes in cancer. J Clin Invest. 2016; 126:1208-15. https://doi.org/10.1172/ JCI81135. [PubMed]

32. Sohn W, Kim J, Kang SH, Yang SR, Cho JY, Cho HC, Shim SG, Paik YH. Serum exosomal microRNAs as novel biomarkers for hepatocellular carcinoma. Exp Mol Med. 2015; 47:e184. https://doi.org/10.1038/emm.2015.68. [PubMed]

33. Liu W, Hu J, Zhou K, Chen F, Wang Z, Liao B, Dai Z, Cao Y, Fan J, Zhou J. Serum exosomal miR-125b is a novel prognostic marker for hepatocellular carcinoma. Onco Targets Ther. 2017; 10:3843-51. https://doi.org/10.2147/ OTT.S140062. [PubMed]

34. Wang Y, Zhang C, Zhang P, Guo G, Jiang T, Zhao X, Jiang J, Huang X, Tong H, Tian Y. Serum exosomal microRNAs combined with alpha-fetoprotein as diagnostic markers of hepatocellular carcinoma. Cancer Med. 2018; 7:1670-9. https://doi.org/10.1002/cam4.1390. [PubMed]

35. Ohno S, Takanashi M, Sudo K, Ueda S, Ishikawa A, Matsuyama N, Fujita K, Mizutani T, Ohgi T, Ochiya T, Gotoh N, Kuroda M. Systemically injected exosomes targeted to EGFR deliver antitumor microRNA to breast cancer cells. Mol Ther. 2013; 21:185-91. https://doi. org/10.1038/mt.2012.180. [PubMed]

36. Mizrak A, Bolukbasi MF, Ozdener GB, Brenner GJ, Madlener S, Erkan EP, Strobel T, Breakefield XO, Saydam O. Genetically engineered microvesicles carrying suicide mRNA/protein inhibit schwannoma tumor growth. Mol Ther. 2013; 21:101-8. https://doi.org/10.1038/mt.2012.161. [PubMed]

37. Ha D, Yang N, Nadithe V. Exosomes as therapeutic drug carriers and delivery vehicles across biological membranes: current perspectives and future challenges. Acta Pharm Sin B. 2016; 6:287-96. https://doi.org/10.1016/j. apsb.2016.02.001. [PubMed]

38. Bunggulawa EJ, Wang W, Yin T, Wang N, Durkan C, Wang Y, Wang G. Recent advancements in the use of exosomes as drug delivery systems. J Nanobiotechnology. 2018; 16:81. https://doi.org/10.1186/s12951-018-0403-9. [PubMed]

39. Morishita M, Takahashi Y, Nishikawa M, Takakura Y. Pharmacokinetics of Exosomes-An Important Factor for Elucidating the Biological Roles of Exosomes and for the Development of Exosome-Based Therapeutics. J Pharm Sci. 2017; 106:2265-9. https://doi.org/10.1016/j. xphs.2017.02.030. [ubMed]

40. Liang G, Kan S, Zhu Y, Feng S, Feng W, Gao S. Engineered exosome-mediated delivery of functionally active miR-26a 
and its enhanced suppression effect in HepG2 cells. Int $\mathbf{J}$ Nanomedicine. 2018; 13:585-99. https://doi.org/10.2147/ IJN.S154458. [PubMed]

41. Zhao S, Li J, Zhang G, Wang Q, Wu C, Zhang Q, Wang H, Sun P, Xiang R, Yang S. Exosomal miR-451a Functions as a Tumor Suppressor in Hepatocellular Carcinoma by Targeting LPIN1. Cell Physiol Biochem. 2019; 53:19-35. https://doi.org/10.33594/000000118. [PubMed]

42. Baldari S, Di Rocco G, Magenta A, Picozza M, Toietta G. Extracellular Vesicles-Encapsulated MicroRNA-125b Produced in Genetically Modified Mesenchymal Stromal Cells Inhibits Hepatocellular Carcinoma Cell Proliferation. Cells. 2019; 8:E1560. https://doi.org/10.3390/cells8121560. [PubMed]

43. Lou G, Song X, Yang F, Wu S, Wang J, Chen Z, Liu Y. Exosomes derived from miR-122-modified adipose tissuederived MSCs increase chemosensitivity of hepatocellular carcinoma. J Hematol Oncol. 2015; 8:122. https://doi. org/10.1186/s13045-015-0220-7. [PubMed]

44. Lou G, Chen L, Xia C, Wang W, Qi J, Li A, Zhao L, Chen Z, Zheng M, Liu Y. MiR-199a-modified exosomes from adipose tissue-derived mesenchymal stem cells improve hepatocellular carcinoma chemosensitivity through mTOR pathway. J Exp Clin Cancer Res. 2020; 39:4. https://doi. org/10.1186/s13046-019-1512-5. [PubMed]

45. Zhang Y, Choop M, Qin Y, Li C, Millman M, Zhang Z. Engineered exosomes with elevation of miR-214 enhance anti-ovarian cancer effects of carboplatin. ISEV \& MRS Joint Meeting. Nashville: Vanderbilt Univeristy; 2019.

46. Zhuang LK, Yang YT, Ma X, Han B, Wang ZS, Zhao QY, Wu LQ, Qu ZQ. MicroRNA-92b promotes hepatocellular carcinoma progression by targeting Smad7 and is mediated by long non-coding RNA XIST. Cell Death Dis. 2016; 7:e2203. https://doi.org/10.1038/cddis.2016.100. [PubMed]

47. Azumi J, Tsubota T, Sakabe T, Shiota G. miR-181a induces sorafenib resistance of hepatocellular carcinoma cells through downregulation of RASSF1 expression. Cancer Sci. 2016; 107:1256-62. https://doi.org/10.1111/cas.13006. [PubMed]

48. Sohn BH, Park IY, Shin JH, Yim SY, Lee JS. Glutamine synthetase mediates sorafenib sensitivity in beta-cateninactive hepatocellular carcinoma cells. Exp Mol Med. 2018; 50:e421. https://doi.org/10.1038/emm.2017.174. [PubMed]

49. Liu X, Xu J, Wang S, Yu X, Kou B, Chai M, Zang Y, Chen D. Synergistic inhibitory effects on hepatocellular carcinoma with recombinant human adenovirus Aspp2 and oxaliplatin via p53-independent pathway in vitro and in vivo. Int J Oncol. 2017; 51:1291-9. https://doi.org/10.3892/ ijo.2017.4105. [PubMed]

50. Li R, Wang Y, Zhang X, Feng M, Ma J, Li J, Yang X, Fang F, Xia Q, Zhang Z, Shang M, Jiang S. Exosome-mediated secretion of LOXL4 promotes hepatocellular carcinoma cell invasion and metastasis. Mol Cancer. 2019; 18:18. https:// doi.org/10.1186/s12943-019-0948-8. [PubMed]
51. Ren WW, Li DD, Chen X, Li XL, He YP, Guo LH, Liu LN, Sun LP, Zhang XP. MicroRNA-125b reverses oxaliplatin resistance in hepatocellular carcinoma by negatively regulating EVA1A mediated autophagy. Cell Death Dis. 2018; 9:547. https://doi.org/10.1038/s41419-018-0592-Z. [PubMed]

52. Costa-Silva B, Aiello NM, Ocean AJ, Singh S, Zhang H, Thakur BK, Becker A, Hoshino A, Mark MT, Molina H, Xiang J, Zhang T, Theilen TM, et al. Pancreatic cancer exosomes initiate pre-metastatic niche formation in the liver. Nat Cell Biol. 2015; 17:816-26. https://doi. org/10.1038/ncb3169. [PubMed]

53. Mashouri L, Yousefi H, Aref AR, Ahadi AM, Molaei F, Alahari SK. Exosomes: composition, biogenesis, and mechanisms in cancer metastasis and drug resistance. Mol Cancer. 2019; 18:75. https://doi.org/10.1186/s12943-0190991-5. [PubMed]

54. Kulkarni B, Kirave P, Gondaliya P, Jash K, Jain A, Tekade RK, Kalia K. Exosomal miRNA in chemoresistance, immune evasion, metastasis and progression of cancer. Drug Discov Today. 2019; 24:2058-67. https://doi.org/10.1016/j. drudis.2019.06.010. [PubMed]

55. Greening DW, Gopal SK, Mathias RA, Liu L, Sheng J, Zhu HJ, Simpson RJ. Emerging roles of exosomes during epithelial-mesenchymal transition and cancer progression. Semin Cell Dev Biol. 2015; 40:60-71. https://doi. org/10.1016/j.semcdb.2015.02.008. [PubMed]

56. Chen L, Guo P, He Y, Chen Z, Chen L, Luo Y, Qi L, Liu Y, Wu Q, Cui Y, Fang F, Zhang X, Song T, Guo H. HCCderived exosomes elicit HCC progression and recurrence by epithelial-mesenchymal transition through MAPK/ERK signalling pathway. Cell Death Dis. 2018; 9:513. https://doi. org/10.1038/s41419-018-0534-9. [PubMed]

57. Fonsato V, Collino F, Herrera MB, Cavallari C, Deregibus MC, Cisterna B, Bruno S, Romagnoli R, Salizzoni M, Tetta C, Camussi G. Human liver stem cell-derived microvesicles inhibit hepatoma growth in SCID mice by delivering antitumor microRNAs. Stem Cells. 2012; 30:1985-98. https://doi.org/10.1002/stem.1161. [PubMed]

58. Bruno S, Collino F, Deregibus MC, Grange C, Tetta C, Camussi G. Microvesicles derived from human bone marrow mesenchymal stem cells inhibit tumor growth. Stem Cells Dev. 2013; 22:758-71. https://doi.org/10.1089/ scd.2012.0304. [PubMed]

59. Horibe S, Tanahashi T, Kawauchi S, Murakami Y, Rikitake Y. Mechanism of recipient cell-dependent differences in exosome uptake. BMC Cancer. 2018; 18:47. https://doi. org/10.1186/s12885-017-3958-1. [PubMed]

60. Wang F, Lv P, Liu X, Zhu M, Qiu X. microRNA-214 enhances the invasion ability of breast cancer cells by targeting p53. Int J Mol Med. 2015; 35:1395-402. https:// doi.org/10.3892/ijmm.2015.2123. [PubMed]

61. Derfoul A, Juan AH, Difilippantonio MJ, Palanisamy N, Ried T, Sartorelli V. Decreased microRNA-214 levels in breast cancer cells coincides with increased cell 
proliferation, invasion and accumulation of the Polycomb Ezh2 methyltransferase. Carcinogenesis. 2011; 32:1607-14. https://doi.org/10.1093/carcin/bgr184. [PubMed]

62. Penna E, Orso F, Cimino D, Tenaglia E, Lembo A, Quaglino E, Poliseno L, Haimovic A, Osella-Abate S, De Pitta C, Pinatel E, Stadler MB, Provero P, et al. microRNA-214 contributes to melanoma tumour progression through suppression of TFAP2C. EMBO J. 2011; 30:1990-2007. https://doi.org/10.1038/emboj.2011.102. [PubMed]

63. Chan KT, Lung ML. Mutant p53 expression enhances drug resistance in a hepatocellular carcinoma cell line. Cancer Chemother Pharmacol. 2004; 53:519-26. https://doi. org/10.1007/s00280-004-0767-4. [PubMed]

64. Callaghan R, Luk F, Bebawy M. Inhibition of the multidrug resistance P-glycoprotein: time for a change of strategy? Drug Metab Dispos. 2014; 42:623-31. https://doi. org/10.1124/dmd.113.056176. [PubMed]

65. Li J, Duan B, Guo Y, Zhou R, Sun J, Bie B, Yang S, Huang C, Yang J, Li Z. Baicalein sensitizes hepatocellular carcinoma cells to 5-FU and Epirubicin by activating apoptosis and ameliorating P-glycoprotein activity. Biomed Pharmacother. 2018; 98:806-12. https://doi.org/10.1016/j. biopha.2018.01.002. [PubMed]

66. Dong J, Zhai B, Sun W, Hu F, Cheng H, Xu J. Activation of phosphatidylinositol 3-kinase/AKT/snail signaling pathway contributes to epithelial-mesenchymal transitioninduced multi-drug resistance to sorafenib in hepatocellular carcinoma cells. PLoS One. 2017; 12:e0185088. https://doi. org/10.1371/journal.pone.0185088. [PubMed]

67. Chan JY, Chu AC, Fung KP. Inhibition of P-glycoprotein expression and reversal of drug resistance of human hepatoma HepG2 cells by multidrug resistance gene (mdr1) antisense RNA. Life Sci. 2000; 67:2117-24. https://doi. org/10.1016/s0024-3205(00)00798-0. [PubMed]

68. Rigalli JP, Ciriaci N, Arias A, Ceballos MP, Villanueva SS, Luquita MG, Mottino AD, Ghanem CI, Catania VA, Ruiz ML. Regulation of multidrug resistance proteins by genistein in a hepatocarcinoma cell line: impact on sorafenib cytotoxicity. PLoS One. 2015; 10:e0119502. https://doi.org/10.1371/journal.pone.0119502. [PubMed]

69. Chen K, Xiao H, Zeng J, Yu G, Zhou H, Huang C, Yao W, Xiao W, Hu J, Guan W, Wu L, Huang J, Huang Q, et al. Alternative Splicing of EZH2 pre-mRNA by SF3B3 Contributes to the Tumorigenic Potential of Renal Cancer. Clin Cancer Res. 2017; 23:3428-41. https://doi. org/10.1158/1078-0432.CCR-16-2020. [ [PubMed]
70. Chen S, Pu J, Bai J, Yin Y, Wu K, Wang J, Shuai X, Gao J, Tao K, Wang G, Li H. EZH2 promotes hepatocellular carcinoma progression through modulating miR-22/ galectin-9 axis. J Exp Clin Cancer Res. 2018; 37:3. https:// doi.org/10.1186/s13046-017-0670-6. [PubMed]

71. Cui S, Sun Y, Liu Y, Liu C, Wang J, Hao G, Sun Q. MicroRNA137 has a suppressive role in liver cancer via targeting EZH2. Mol Med Rep. 2017; 16:9494-502. https:// doi.org/10.3892/mmr.2017.7828. [PubMed]

72. Pu M, Chen J, Tao Z, Miao L, Qi X, Wang Y, Ren J. Regulatory network of miRNA on its target: coordination between transcriptional and post-transcriptional regulation of gene expression. Cell Mol Life Sci. 2019; 76:441-51. https://doi.org/10.1007/s00018-018-2940-7. [PubMed]

73. Xin H, Wang F, Li Y, Lu QE, Cheung WL, Zhang Y, Zhang ZG, Chopp M. Secondary Release of Exosomes From Astrocytes Contributes to the Increase in Neural Plasticity and Improvement of Functional Recovery After Stroke in Rats Treated With Exosomes Harvested From MicroRNA 133b-Overexpressing Multipotent Mesenchymal Stromal Cells. Cell Transplant. 2017; 26:243-57. https://doi. org/10.3727/096368916X693031. [PubMed]

74. Xin H, Li Y, Buller B, Katakowski M, Zhang Y, Wang X, Shang X, Zhang ZG, Chopp M. Exosome-mediated transfer of miR-133b from multipotent mesenchymal stromal cells to neural cells contributes to neurite outgrowth. Stem Cells. 2012; 30:1556-64. https://doi.org/10.1002/stem.1129. [PubMed]

75. Lu Y, Jiang F, Jiang H, Wu K, Zheng X, Cai Y, Katakowski M, Chopp M, To SS. Gallic acid suppresses cell viability, proliferation, invasion and angiogenesis in human glioma cells. Eur J Pharmacol. 2010; 641:102-7. https://doi. org/10.1016/j.ejphar.2010.05.043. [PubMed]

76. Liu XS, Chopp M, Zhang RL, Tao T, Wang XL, Kassis H, Hozeska-Solgot A, Zhang L, Chen C, Zhang ZG. MicroRNA profiling in subventricular zone after stroke: MiR-124a regulates proliferation of neural progenitor cells through Notch signaling pathway. PLoS One. 2011; 6:e23461. https://doi.org/10.1371/journal.pone.0023461. [PubMed] 